\title{
Proton Pompa İnhibitörlerinin Uzun Dönem Kullanımlarındaki Etkileri
}

\author{
Effects of Proton Pump Inhibitors on Long-Term Use
}

Murat İSPİROĞLU, Kadir GIŞ̧̇̇, Bülent KANTARÇEKEN

Kahramanmaraş Sütçü İmam Üniversitesi Tip Fakültesi Gastroenteroloji BD, Kahramanmaraş, Türkiye

Geliş tarihi: 17.02.2020 Kabul tarihi: 12.04.2020 DOI: 10.17517/ksutfd.690248

\section{Özet}

Proton pompa inhibitörleri (PPI) iyi bir güvenlik profiline sahip ve toplumda çok sık kullanılan ajanlardır. Sık kullanılan bu ilaçların yan etkisi konusunda net veriler olmamakla birlikte, bu yan etkilerin ilacın uzun süre kullanımından kaynaklanan mide asiti baskılanmasına bağlı olduğu düşünülmektedir. Biz burada daha çok zeminde oluşan uzamış hipoklorhidri ve hipergastrineminin neoplastik sonuçları, malabsorbsiyon, enfeksiyonlar ve diğer nedenler ana başlıkları altında konuyu tartışmaya çalıştık.

Anahtar Kelimeler: Proton pompa inhibitörleri, Uzun dönem, Yan etkiler

\begin{abstract}
Proton pump inhibitors (PPI) have a good safety profile and are frequently used in community. Although there are no clear data on the side effects of these frequently used drugs, these side effects are thought to be due to the suppressed stomach acid as a result of long-term use. Here, we tried to discuss the issue under the main headings of neoplastic results, malabsorption, infections and other causes of prolonged hypochlorhydria and hypergastrinemia occurring on the ground.
\end{abstract}

Keywords: Proton pump inhibitors, Long term, Side effects

Yazışma Adresi: Murat İSPİROĞLU Sütçü İmam Ünversitesi Tip Fakültesi, Gastroenteroloji Bilim Dalı, Kahramanmaraş,Türkiye Telefon: 05053461832 e-mail: muratispiroglu@yahoo.com ORCID No (S1rasıyla): 0000-0002-0655-7235, 0000-0003-4082-4832, 0000-0003-

4214-817 


\section{GİRIŞ}

Proton pompa inhibitörleri (PPI) tüm asit-ilişkili hastalıkların tedavisinde hali hazırda en etkili ilaçlardır ve yaygın olarak kullanılmaktadır. Genellikle iyi bir güvenlik profiline sahiptirler. Olgu sunumları şeklinde bildirilen interstisyel nefrit, hepatit gibi ciddi yan etkileri oldukça nadirdir. PPI'lara bağlı minör yan etki riski yaklaşık \%1-3 olup, yan etkiler nedeniyle ilacı kesme oranı \%1-2'dir (1,2). PPI kullanımı için uzun dönem ile ne kastedildiği net değildir. Kılavuzlarda belli bir tanımlama yer almamaktadır. Bu durumda, standart bir tedavi süresinden daha uzun süreli kullanım, uzun süre olarak kabul edilebilir. Kullanım süresi uzadıkça, aslında ilacın farmakokinetiği ve/veya etkileșimlerinden değil, neden olduğu asit baskılamasının getirebileceği sonuçlardan kaygı duyulmaktadır. Yani temel kaygı uzamış hipoklorhidrinin getireceği hipergastrinemi ve buna bağlı gelişebilecek gastrik atrofi, neoplazi gibi durumlar iken ek olarak hipoklorhidri, enfeksiyonlara ve malabsorpsiyona da predispozisyon oluşturmaktadır. Günümüzde neoplazi gelişimi yönünden net bir kanaat oluşmamışken, enfeksiyonlarda artış ve malabsorbsiyon konusu daha nettir. Nitekim US Food and Drug Administration (FDA) ve American College of Gastroenterology (ACG) bu durumlarla ilgili bildirimlerde bulunmuştur $(3,4)$. Bugüne kadar yapılan en uzun süreli (15 yıla kadar, pantaprazol) PPI kullanımlı güvenilirlik çalışmasında PPI kullanımı emniyetli olarak bulunmuştur (5). Ancak uzun süre PPI kullanılması ile hipergastrinemi, gastrik polipler, karsinoid, gastrik ve kolorektal kanser, enterik infeksiyonlar, toplum kökenli pnömoni, başlica kalsiyum, magnezyum, B12 vitamini ve demir v.b. mikroelement eksikliği gibi sonuçların da olabileceği bildirilmektedir. Bu etkilerin, bilinmesi uzun süre PPI kullanacak olan hastalarda daha dikkatli olunmasını ve tedbir alınmasını sağlayacaktır. Sonuçta, temel olarak dört ana konu karşımıza çıkmaktadır;

\section{Uzamış hipoklorhidri ve hipergastrineminin neoplas- tik sonuçları}

2. Malabsorbsiyon ve sonuçları

\section{Enfeksiyonlar}

\section{Diğerleri}

\section{UZAMIŞ HIPOKLORHIDDİ VE HIPERGASTRINEMININ NEOPLASTIK SONUÇLARI}

PPI kullanılması ile azalan asit sekresyonu, gastrin salınımını artırarak hipergastrinemi durumu oluşturur. Gastrin hormonunun trofik etkisinden dolayı, uzun süreli PPI kullanımının gastrik polip, gastrik kanser, gastrik karsinoid ve kolorektal kanser riskini artıracağı öngörülmektedir. Ayrıca mide asiti, bakteri kolonizasyonunu önleyerek bakterilerin nitrozamin gibi kanserojen madde üretimini önler. Ancak PPI tarafından mide asit baskılanması bu dengeyi değisştirebilir.

\section{Atrofik Gastrit}

Uzun süreli PPI kullanıcılarında kronik atrofik gastrit geliştiği gözlenmiştir. Asit süpresyonu Helicobakter Pylori (HP) ile enfekte kişilerde gastrit paternini değiştirerek korpus dominant gastrite neden olmakta atrofik gastrit oluşturmaktadır. Bu durumda mantıklı olan uzun süre PPI almayı gerektiren durumlarda H.pylori'yi eradike etmektir (6). Nitekim bu öneri verilmiştir. Ancak sonraki çalışmalar bu görüşü desteklememiştir. Ayrıca, bu hastalarda korpus intestinal metaplazisi nadirdir ve displazi veya neoplazm gözlenmemiştir (7).

\section{Fundus polipleri}

Uzun süre PPI kullanan bazı hastalarda mide fundusunda glandüler ve hiperplastik poliplerin gelişebileceği bilinmektedir. Vaka sunumları ve vaka serileri, fundus gland poliplerinin uzun dönem PPI tedavisi ile ilişkili olduğunu, PPI kesilmesinden sonra gerilediğini ve insidansının 1 yıldan uzun süre PPI kullananlarda \%1-36 olduğu bildirmiştir (8). Oluşan poliplerin büyük çoğunluğu benigndir ve endoskopik takip veya eksizyonu önerilmez. Ancak Familial Adenomatozis Polipozisli hastalarda displazi riski yönünden takip edilmelidir (9). Çok sayıda araştırmacı ile yapılan prospektif bir çalışmada fundik polip gelişiminin H.pylori yokluğu ile ilişkili olduğu hiperplastik polip gelişiminin ise serum gastrin seviyesi ve H.pylori ile ilişkili olduğu bildirilmiştir (10).

\section{Karsinoid Tümör Gelişimi}

Uzun süre PPI kullanılmasının, enterokromafin benzeri hücre (Enterocromaffin Like Cell -ECL) hiperplazisine yol açarak, insanlarda karsinoid tümör gelişebileceğine dair öngörüler mevcuttur. Gerçektende uzun süreli PPI kullanılması, hipergastrinemi ve ECL hücrelerinde hiperplazi ile sonuçlanabilir. Bu da nöroendokrin tümör gelişimi için kaygıları artırmaktadır. Gerçektende son 50 yılda karsinoid insidansı artmıştır (11). Sıçan deneylerinde, uzun süre PPI kullanımı ile gastrik karsinoid tümör geliştiği rapor edilmiştir. Son yapılan araştırmalarda, GÖRH nedeniyle 12-15 yll boyunca PPI kullanan hastalarda, hipergastrineminin diğer nedenlerinde (atrofik gastritis, gastrinoma) olduğu gibi, PPI kullanımına bağlı oluşan hipergastrinemide de, insanlarda ve rodentlerde ECL hücre karsinoidlerinde ve gastrik kanserde artış olduğu tespit edilmiş̧ir $(12,13)$. Ancak randomize klinik çalışmalarda, insanlarda, en az 3 yıllık PPI kullanımı ile böyle bir durum bildirilmemiştir (14). Ayrıca 5 yıllık PPI kullanımı ile ECL hücrelerde herhangi bir artış olmadığ gözlenmiştir (15). Uzun süre PPI kullanan hastaların populasyon çalışmalarında bu nadir görülen tümörlerin insidansında bir artış olmasına rağmen, PPI'lerinin insanlarda böyle bir etkisinin olup olmadığını değerlendiren bir çalışma henüz yoktur. Bu ilişkinin olup olmadığını ortaya koyacak ileri ve geniş çalışmalara ihtiyaç vardır. 


\section{Gastrik Malignensi}

Uzun süre PPI kullanılması ile gastrik kanser gelişimi öngörüsünde temel nokta atrofik gastrit - intestinal metaplazi - adenokanser zinciridir. Özellikle PPI kullanımı sürecinde izlenen korpus dominant HP enfeksiyonu saptananlarda bu riskte artış olduğu belirtilmiş (16). Ancak, sonraki çalışmalar uzun süreli PPI kullanımının HP pozitif vakalarda atrofiyi hızlandırmadığını göstermiştir $(6,17)$. Bu konu halen tartışımaktadır ve bu konuda fikir birliği olmamakla birlikte uzun süre PPI tedavisi almak zorunda olanlarda HP eradikasyonu yapılması akılcı bir yaklaşım olarak önerilmektedir (18). Maastricht konsensus paneli uzun süre PPI kullanacak $\mathrm{H}$. pylori pozitif bireylere eradikasyon tedavisi önermekle birlikte ${ }^{18}$ "American College of Gastroenterology" benzer öneriyi yapmamıştır (19). Bu konuda ileri çalışmalara ihtiyaç vardır.

\section{Mide dıșı kanser}

Gastrin, pek çok epitel hücresinde trofik etkiye sahiptir. Bazı hayvan deneylerinde kolorektal kanser oluşumunu tetiklediği rapor edilsede hipergastrinemi-kolorektal kanser ilişkisi konusunda çelişkili yayınlar mevcuttur (20). İnsanlarda PPI ile kolorektal kanserin arttı̆̆ına dair güçlü deliller yoktur. İnsanlarda bazı çalışmalardan hipergastrinemi ile kanser arasında pozitif ilişkiden bahsedilse de (21), büyük vaka-kontrol çalışmalarında, uzun dönem PPI kullanımı ile kolorektal kanser, adenomatöz polip sıklı̆̆ı, büyümesi ve histolojisi arasında ilişki saptanmamıştır (22-24).

\section{ENFEKSIYYONLAR}

\section{Enterik enfeksiyonlar}

Midenin güçlü asit ortamı, patojen mikroorganizmalar için önemli bir bariyerdir ve bakteriler aside çok duyarlıdır. Gastrik asitin güçlü ve uzun süreli inhibisyonu ile normalde asit ile önlenen enterik enfeksiyon riski artmaktadır. Kolonizasyonun sıklı̆̆ ve tipi gastrik asit süpresyonunun süre ve derecesine bağlıdır. PPI kullanımı ile ilişkisi en iyi dökümante edilmiş patojen Clostridium Difficile (C. Difficile) ve ona bağlı gelişen diyaredir $(25,26)$. Oldukça yüksek hasta sayılı bir meta- analiz de, birlikte antibiyotik kullanmasalar bile, PPI alanlar da C. Difficile riskinde anlamlı artış saptanmıştır (27). Prospektif bir çalışmada hastanede yatan ve bu sırada antibiyotik ve PPI alan hastalarda, C. Difficile ile ilişkili diyarenin 5 kat arttığı bildirilmiştir (28). Ayrıca, 65 yaş üstü hastalarda, beraberinde antibiyotik kullananlarda, inflamatuvar barsak hastalığı ve böbrek yetmezliği olanlarda C. Difficile ile ilişkili diyare oluşma riskinin 2.9-3.7 oranında arttı̆̆ bildirilmiştir (29). Ayrıca PPI kullanımının sirotik hastalarda enfeksiyon riskini artırdığı bildirilmiştir (30). Her ne kadar meta-analizlerdeki çalışmalar oldukça heterojen olsa da, PPI kullanımı ile güçlü ilişki nedeniyle, FDA 2012 yılında persistan diyare durumunda C. Difficile yönünden tetkik edilmesini önermiştir (31). PPI kullanımı ile ilişkili olduğu düşünülen Camphylobacter ve Salmonella enfeksiyonları da bildirilmiştir.

\section{Pnömoni}

PPI kullanımına bağlı azalan asiditiye bağlı olarak üst gastrointestinal kanalda patojenlerin kolonizasyonunda kolaylaşma ve aspirasyonla hem toplum kökenli hem de hastane kökenli pnömoni olasıllığında artış olabileceği bildirilmiştir $(32,33)$. Ancak sonuçlar halen kafa karıştırıcıdır (34). Bir araştırmada uzun süreli değilde, son 30 gün içinde PPI'nın yeni başlanmış olmasının, pnömoni riskini arttırdığı gösterilmiş (35). Pnömoni riskinin artmadığını bildiren yayınlar da vardır $(36,37)$. Sonuçta PPI kullanımı ile pnömoni arasında çok net bir ilişki bulunmamakla birlikte, hastanede yatan, immünsuprese ve kronik hastalığı olanlarda daha çok akut kullanımla risk artıyor görünmektedir. Nitekim ACG uzun dönem kullanım için risk belirtmezken, kısa kullanımlarda riskin artabileceğini belirtmektedir.

\section{MALABSORBSIYYON}

PPI kullanımı ile üst gastrointestinal traktın bariyer fonksiyonunun etkilendiği düşünülmektedir. PPI’nin transmukozal olarak, endojen peptid ve proteinlerde kaçak olmasına neden olabileceği düşünülmüştür. Klinik önemi net değildir. Esomeprazolun üst Gastrointestinal sistem (GIS)'de bariyer fonksiyonunu etkileyip etkilemediğini anlamak için bir araştırma yapılmış ve Esomeprazolun günler içinde hızlı bir şekilde, transmukozal kaçağa neden olduğu tespit edilmiş, ilaç bırakıldıktan sonra ise kaçak düzelmiştir (38). Uzun süreli asit baskılanması sonucu hem metabolik defektler ve hem de aşırı bakteri çoğalması özellikle kalsiyum, magnezyum, B12 vitamini ve demir absorbsiyonunda bozukluğa neden olabilirler.

\section{Kalsiyum malabsorbsiyonu}

Uzun süreli PPI kullanımının, hem kalsiyum malabsorbsiyonuna hem de hipergastrinemiye bağlı paratroid hiperplazisine bağlı olarak, (beraberinde B12 vitamini eksikliği de varsa ayrıca hiperhomosisteinemi ve osteoblastik aktivite azalması ile), kemik yapısının bozulmasına (Osteoporoz-kemik dansitesinde azalma) ve kırıklara neden olabileceği düşünülmektedir. Ancak bu konuda çok sayıda çalışma yapılmasına rağmen sonuçlar halen çelişkilidir. Bir çalışmada 13556 kalça kırı̆̆ı vakası, 135386 kontrolle karşılaştırılmış, 1 yıldan uzun süre (1- 15 yıl) PPI kullanımının kalça kırı̆̆ı riskini 1.44 kat arttırdığı ve PPI dozu arttıkça kırık riskinin 2,65 kata çıktığı tesbit edilmiştir (39). Vaka-kontrol çalışmalarında özellikle 50 yaş üstü ve en az bir kırık riskine sahip olanlarda kemik yoğunluğunda azalmaya bağlı olarak risk arttığı bildirilirken, prospektif kohort çalışmalarda böyle bir risk bildirilmemiştir $(40,41)$. Uzun süreli (Beş yll ve daha fazla) PPI kullanan bireylerde kırık riski arttığını belirten çalışmalar vardır. Bunun yanı sıra sadece osteoporozu ve steroid kullanımı olanlarda riskin arttı̆̆ını, diğerlerinde değişmediğini bildiren makaleler de mevcuttur $(39,42,43)$. FDA Mayis 2010 tarihinde ilacın prospektüs bilgisine "kalça ve omurga kırık riskini artırması muhtemeldir" cümlesini eklemiştir. FDA Mart 2011'de PPI kullananlarda muhtemel artmış kı- 
rık riskini güncellemiştir ve buda PPI kullananlarda dikkatli olunmasını ve etkili en düșük doz ve süre kullanımını öneren Kanada kılavuzu ile paraleldir (44,45). Ancak ACG 2013 GERD kılavuzunda "Osteoporoz varlığı PPI kullanımı için kontrendikasyon değildir” denilmektedir. Bugün itibariyle uzun dönem PPI kullanan hastalara rutin farmakolojik osteoporoz profilaksisi, kalsiyum replasmanı ya da kemik mineral dansitesi taraması önermek için yeterli delil yoktur ve başka ek kırık riski taşımayan osteoporozlu hastalarda tedavi kesilmesine gerek yoktur (3). Bir prospektif kohort çalışmasında PPI kullananların yaşam stilleri ve ek medikasyonlarının kırık riski açısından önemli olduğunu bildirmektedir (46). Yüksek doz ve 1 yıldan uzun süreli PPI kullanımı özellikle 50 yaş üzeri ve yandaş kırık riskine sahip olanlarda daha fazla kırık riski taşımaktadır $(39,42)$. Multiple risk faktörü olan hastalarda kemik dansite çalışmaları yapılabilir ve ayrıca kalsiyum replasmanı yapılması gerekirse asidik ortama bağımlı olmayan kalsiyum sitrat tercih edilmelidir.

\section{Magnezyum Malabsorbsiyonu}

PPI kullanımı sırasında bazen oldukça ciddi tablolara neden olan magnezyum düşüklükleri saptanmıștır. PPI kullanımı, asit süpresyonu sonucu, protein üretim defektine ve intestinal permeabilite bozukluğuna yol açarak hipomagnezemiye neden olmaktadır $(47,48)$. Bundan dolayı FDA, uzun süre PPI kullanımı sonucunda, 2006 yılından beri yaklaşık 30 ciddi hipomagnezemi tespit edilmesi nedeniyle Mart 2011 de özellikle 1 yıldan uzun süreli PPI kullanılacaksa hipomagnezemi riski yönünden uyarı yayımlamıştır ve tedavi öncesi ve sırasında aralıklarla magnezyum düzeyine bakılmasını önermiştir (49). PPI kesilince hipomagnezemi genellikle düzelmektedir (48). ACG kılavuzunda ise kronik PPI kullanımı ile ilişkili hipomagnezemiden bahsedilmemektedir.

\section{B12 Vitamini Malabsorbsiyonu}

B12 vitamini'nin y1llarca yetebilecek miktarda depolanmasından dolayı eksikliği ancak çok uzun süreli asit baskılanması ile ortaya çıkar. Yaşlılarda PPI kullananlarda eksikliği 4.45 kat fazla bulunmuştur (50). Ancak çalışmalar çelişkilidir. Genel kanı uzun süre PPI kullananlarda serum B12 vitamini seviyesinin takibinin gerektiği yönündedir (51). PPI kullanımının B12 vitamini emilimini azalttığı ile ilgili bir kaç gözlemsel çalışma vardır, ancak klinik olarak yapılmış prospektif çalışma azdır. Prospektif çalışmalarda serum B12 vitamini düzeylerinde azalma gösterilmiş olmakla birlikte laboratuvar değerleri normal aralıkta bulunmuştur ve PPI tedavisine bağl1 B12 vitamini düşüklüğü olan hastalarla ilgili nöropatik değişiklikler bildirilmemiştir (52). Güncel yaklaşım olarak, PPI kullanan hastalara B12 vitamini eksikliği için rutin test yapılması önerilmez. Ancak, yaşlılarda B12 vitamini düzeyi düşüklügü daha fazla saptandığından, uzun dönem PPI kullanan yaşlı veya malnutrisyonu olan bireylerde B12 vitamini düzeyi kontrolü uygun olabilir.

\section{Demir malabsorbsiyonu}

Diyetteki demir emilimi için gastrik asite ihtiyaç vardır. Mide asiti alınan demiri daha kolay emilebilen ferröz forma dönüştürür. PPI kullanımı ile anlamlı klinik oluşmaz ancak oral demir tedavisini etkileyebileceği düşünülür (53). Uzun süre PPI kullanan hemokromatozisli hastalarda flebotomi ihtiyacında azalma bildirilmiştir. Literatürde bu konuda yapılmış prospektif bir çalışma yoktur ve PPI tedavisi alanlarda rutin demir eksikliği taraması önerilmemiştir (54).

\section{DİĞERLERİ}

\section{Mikroskobik kolitis}

Mikroskobik kolit; kronik sulu diyare, kramp tarzı karın ağrısı, endoskopik olarak normal kolon mukozal görünümü ve biyopside kronik inflamatuvar süreç olması ile karakterizedir (55). Son zamanlarda, uzun süreli PPI kullananlarda kollajenöz kolit ve lenfositik kolit olguları vaka veya vakalar şeklinde artan sayıda bildirilmiştir $(56,57)$. Vaka-kontrol çalışmalarından da benzer sonuçlar bildirilmiştir (58). Tedaviye yanıtsız diyare vakalarında şüphelenilmesi gerekir.

\section{İlaç Etkileșimi}

PPI ile klinik anlamlı ilaç etkileşimi nadirdir. Özellikle omeprazol - clopidogrel etkileşimi ile azalan clopidogrel etkisinden dolayı kardiyoasküler risk oluşabilir (59). Bundan dolayı US Food and Drug Administration (FDA) 2009 yılında bu konuda uyarı yayınlamıştır (60).

\section{SONUÇ}

PPI'lar genel olarak iyi tolere edilen üstün güvenlik profiline sahip ilaçlardır. Dünyada en yaygın kullanılan ilaçlardan olup, uzun dönem kullanımı sonucu ortaya çıkan durumlar ile ilgili artan sayıda veriye ulaşabilmek daha olası hale gelmiştir. Ancak bu verilerdeki heterojenite öngörülen istenmeyen sonuçlarla ilgili net yorumlar için halen yeterli değildir. Özellikle neoplastik değişimler yönünden yorum yapabilmek için ileri ve geniş çalışmalara ihtiyaç vardır.

\section{KAYNAKLAR}

1. Langtry HD, Wilde MI. Lansoprazole. An update of its pharmacological properties and clinical efficacy in the management of acid-related disorders. Drugs 1997 Sep;54(3):473-500.

2. Laine L, Ahnen D, McClain C, Solcia E, Walsh J H. Potential gastrointestinal effect of long-term acid suppression with proton pump inhibitors. Aliment Pharmacol. Ther 2000;14:651-68.

3. Katz PO, Gerson LB, Vela MF. Guidelines for the diagnosis and management of gastroesophageal reflux disease. Am J Gastroenterol. 2013;108:308-328.

4. http://www.fda.gov/Drugs/DrugSafety/default.htm.

5. Brunner G, Athmann C, Schneider A. Long-term, open-label trial: safety and efficacy of continuous maintenance treatment with pantoprazole for up to 15 years in severe acid-peptic disease. Aliment Pharmacol Ther 2012;36:37-47.

6. Kuipers EJ, Lundell L, Klinkenberg-Knol EC, Havu N, Festen HP, Liedman B, et all. Atrophic gastritis and Helicobacter Pylori 
infection in patients with reflux esophagitis treated with omeprazole or funduplication. N Engl J Med 1996;334:1018-22.

7. Klinkenberg-Knol EC, Nelis F, Dent J, Snel P, Mitchell B, Prichard $\mathrm{P}$, et al. Long-term omeprazole treatment in resistant gastroesophageal reflux disease: Efficacy, safety, and influence on gastric mucosa. Gastroenterology 2000;118:661-9.

8. Jalving M, Koornstra JJ, Wesseling J, Boezen HM, DE Jong S, Kleibeuker JH. Increased risk of fundic gland polyps during long-term proton pump inhibitor therapy. Alim Pharmacol. Ther 2006;24:1341-8.

9. Bianchi LK, Burke CA, Bennett AE, Lopez R, Hasson H, Church JM. Fundic gland polyp dysplasiais common in familial adenomatous polyposis. Clin Gastroenterol Hepatol 2008;6:180-5.

10. Hongo M, Fujimoto K. Gastric Polyps Study Group. Incidence and risk factor of fundic gland polyp and hyperplastic polyp in long-term proton pump inhibitor therapy: A prospective study in Japan. J Gastroenterol. 2010 Jun;45(6):618-24.

11. Modlin IM, Lye KD, Kidd M. A 50-year analysis of 562 gastric carcinoids: Small tumor or larger problem? Am J Gastroenterol 2004;99:23-32.

12. Jianu CS, Lange OJ, Viset T, Qvigstad G, Martinsen TC, Fougner $\mathrm{R}$, et al. Gastric neuroendocrine carcinoma after long-term use of proton pump inhibitör. Scand J Gastroenterol 2012:47:64-7.

13. Jianu CS, Fossmark R, Viset T, Qvigstad G, Sørdal O, Marvik $\mathrm{R}$, et al. Gastric carcinoids after long-term use of a proton pump inhibitor. Aliment Pharmacol Ther 2012;36:644-9.

14. Eslami L, Nasseri-Moghaddam S. Meta-analyses: Does longterm PPI use increase the risk of gastric premalignant lesions? Arch Iran Med. 2013 Aug;16(8):449-58.

15. Thjodleifsson B, Rindi G, Fiocca R, Humphries TJ, Morocutti A, Miller N, et al. A randomized, double-blind trial of the efficacy and safety of 10 and $20 \mathrm{mg}$ rabeprazole compared with $20 \mathrm{mg}$ omeprazole in the maintenance of gastro-oesophageal reflux disease over 5 years. Aliment Pharmacol Ther 2003;17:343-51.

16. Kuipers EJ, Uyterlinde AM, Peña AS, Hazenberg HJ, Bloemena E, Lindeman J, et al. Increase of Helicobacter pylori-associated corpus gastritis during acid supressive therapy: Implications for long-term safety. Am J Gastroenterol 1995; 90:1401-6.

17. Lundell L, Miettinen P, Myrvold HE, Pedersen SA, Thor K, Andersson A, et al. Nordic GERD Study Group: Lack of effect of acid supression therapy on gastric atrophy. Gastroenterology 1999;117:319-26.

18. Malfertheiner P, Megraud F, O’Morain CA, Atherton J, Axon ATR, Bazzoli F, et al. European Helicobacter Study Group. Management of Helicobacter pylori infection--the Maastricht IV/ Florence Consensus Report. Gut 2012;61:646-64.

19. Chey WD, Wong BC. American College of Gastroenterology guideline on the management of Helicobacter pylori infection. Am J Gastroenterol 2007;102:1808-25.

20. Watson SA, Smith AM. Hypergastrinemia promotes adenoma progression in the APC (Min-/+) mouse model of familial adenomatous polyposis. Cancer Res 2001;61(2):625-31.

21. Thorburn CM, Friedman GD, Dickinson CJ, Vogelman J H, Orentreich N, Parsonnet J, et al. Gastrin and colorectal cancer: A prospective study. Gastroenterology 1998;115(2):275-80.

22. Van Soest EM, Van Rossum LGM, Dieleman JP, Van Oijen MGH, Siersema PD, Sturkenboom MCJ, et al. Proton pump inhibitors and the risk of colorectal cancer. Am J Gastroenterol. 2008 Apr;103(4):966-73.

23. Robertson DJ, Larsson H, Friis S, Pedersen L, Baron JA, Sorensen HT, et al. Proton pump inhibitör use and risk of colorectal cancer: a population-based, case-control study. Gastroenterology. 2007 Sep;133(3):755-60.

24. Yang YX, Hennessy S, Propert K, Hwang WT, Sedarat A, Lewis JD, et al. Chronic proton pump inhibitor therapy and the risk of colorectal cancer. Gastroenterology. 2007 Sep;133(3):755-60.

25. Leonard J, Marshall JK, Moayyedi P. Systematic review of the risk of enteric infection in patients taking acid suppression. Am J Gastroenterol 2007;102:2047.

26. Janarthanan S, Ditah I, Adler DG, Ehrinpreis MN. Clostridium Difficile-associated diarrhea and proton pump inhibitor therapy: a meta-analysis. Am J Gastroenterol. 2012;107:1001.

27. Kwok CS, Arthur AK, Anibueze CI, Singh S, Cavallazzi R, Loke YK. Risk of Clostridium Difficile infection with acid suppressing drugs and antibiotics: meta-analysis. Am J Gastroenterol 2012;107(7):1011-19.

28. Loo VG, Bourgault AM, Poirier L, Lamothe F, Michaud S, Turgeon N, et al. Host and pathogen factors for Clostridium Difficile infection and colonization. N Eng J Med 2011;365:1693-703.

29. Dial S, Delaney JAC, Barkun AN, Suissa S. Use of gastric acid-supppressive agents and the risk of community-acquired Clostridium Difficile - associated disease. JAMA 2005;294:298995.

30. Merli M, Lucidi C, De Gregorio V, Giannelli V, Giusto M, Ceccarelli G. The chronic use of beta-blockers and proton pump inhibitors may affect the rate of bacterial infections in cirrhosis. Liver Int. 2015 Feb;35(2):362-9.

31. FDA Drug Safety Communication: Clostridium Difficile-associated diarrhea can be associated with stomach acid drugs known as proton pump inhibitors. (http://www.fda.gov/Drugs/ DrugSafety/ucm290510.htm)

32. Johnstone J, Nerenberg K, Loeb M. Meta analysis: Proton pump use and the risk for community acquired pneumonia. Aliment Pharmacol Ther. 2010;31:1165-77.

33. Eom CS, Jeon CY, Lim JW, Cho EG, Park SM, Lee SK. Use of acid-suppressive drugs and risk of pneumonia: A systematic review and meta-analysis. CMAJ 2011;183:310.

34. Jena AB, Sun E, Goldman DP. Confounding in the association of proton pump inhibitor use with risk of community-acquired pneumonia. J Gen Intern Med 2013;28:223.

35. Sarkar M, Hennesy S, Yang YX. Proton pump inhibitor use and the risk for community aquired pneumonia. Ann Intern Med 2008;149:391-8.

36. Estborn L, Joelsen S. Occurrence of community acquired respiratory tract infection in patients receiving esomeprazole: Retrospective analysis of adverse events in 31 clinical trials. Drug Safety 2008;31:627-36.

37. Sultan N, Nazreno J, Gregor J. Association between proton pump inhibitors and respiratory infections: A systematic review and metaanalysis of clinical trials. Can J Gastroenterol 2008;22:761-6.

38. Mullin JM, Valenzano MC, Whitby M, Lurie D, Schmidt JD, Jain V, et al. Esomeprazole induces upper gastrointestinal tract transmucosal permeability increase. Aliment Pharmacol Ther 2008:28:1317-25.

39. Yang YX, Lewis JD, Epstein S, Metz DC. Long-term proton pump inhibitor therapy and risk of hip fracture. JAMA 2006;296:2947-53.

40. Targownik LE, Lix LM, Leung S, Leslie WD. Proton-pump inhibitor use is not associated with osteoporosis or accelerated bone mineral density loss. Gastroenterology 2010;138:896. 
41. Targownik LE, Leslie WD, Davison KS, Goltzman D, Jamal SA, Kreiger N, et al. The relationship between proton pump inhibitor use and longitudinal change in bone mineral density: a population-based study from the Canadian Multicentre Osteoporosis Study (CaMos). Am J Gastroenterol 2012;107:1361.

42. Targownik LE, Lix LM, Metge CJ, Prior HJ, Leung S, Leslieet WD. Use of proton pump inhibitors and risk of osteoporosis related fractures. CMAJ 2008;179:319-26.

43. Corley DA, Kubo A, Zhao W, Quesenberry C. Proton pump inhibitors and histamine-2 receptor antagonists are associated with hip fractures among at risk patients. Gastroenterology 2010 Jul;139(1):93-101.

44. FDA Drug Safety Communication: Possible increased risk of fractures of the hip, wrist, and spine with the use of proton pump inhibitors. FDA. March 8, 2017. www.fda.gov/drugs/ postmarketdrugsafetyinformationforpatientsandproviders/ ucm213206.htm.

45. Proton pump inhibitors: risk of bone fractures. Health Canada. April 4, 2013. http://healthycanadians.gc.ca/recall-alert-rappel-avis/hc-sc/2013/26523a-eng.php. Accessed April 12, 2020.

46. Khalili H, Huang ES, Jacobson BC, Camargo Jr CA, Feskanich D, Chan AT. Use of proton pump inhibitors and risk of hip fracture in relation to dietary and lifestyle factors: a prospective cohort study. BMJ.2012;344:e372.

47. Cundy T, Dissanayake A. Severe hypomagnesaemia in longterm users of proton-pump in hibitors. Clin Endocrinol (Oxf) 2008;69(2):338-41.

48. Hess MW, Hoenderop JG, Bindels RJ, Drenth JP. Systematic review: hypomagnesaemia induced by proton pump inhibition. Aliment Pharmacol Ther 2012;36(5):405-13.

49. FDA Drug Safety Communication: Low magnesium levels can be associated with long-term use of proton pump inhibitor drugs (PPIs). FDA. March 14, 2011. www.fda.gov/drugs/drugsafety/ucm245011.htm. Accessed April 12, 2020)

50. Valuck RJ, Ruscin JM. A case-control study on adverse effects: $\mathrm{H} 2$ blocker or proton pump inhibitor use and risk of vitamin B12 deficiency in older adults. J Clin Epidemiol 2004;57(4):4228.

51. Heidelbaugh JJ, Metz DC, Yang YX. Proton Pump Inhibitors: are they over-utilised in clinical practice and do they pose significant risk? Int J Clin Pract 2012;66:582-91.

52. Dharmarajan TS, Kanagala MR, Murakonda P, Lebelt AS, Norkus EP. Do acid-lowering agents affect vitamin B12 status in older adults? J Am Med Dir Assoc. 2008 Mar;9(3):162.

53. Ajmera AV, Shastri GS, Gajera MJ, Judge TA. Suboptimal response to ferrous sulfate in iron-deficient patients taking omeprazole. Am J Ther 2012;19:185-9.

54. Hutchinson C, Geissler CA, Powell JJ, Bomford A. Proton pump inhibitors suppress absorption of dietary non-haem iron in hereditary haemochromatosis. Gut 2007;56(9):1291-5.

55. Veress B, Lofberg R, Bergman L. Microscopic colitis syndrome. Gut 1995;36:880-6.

56. Wilcox GM, Mattia AR. Microscopic colitis associated with omeprazole and esomeprazole exposure. J Clin Gsatroenterol 2009:43;551-3.

57. Corleto VD, Festa S, Di Giulio E, Annibale B. Proton pump inhibitor therapy and potential long-term harm. Curr Opin Endocrinol Diabetes Obes. 2014 Feb;21(1):3-8.

58. Keszthelyi D, Jansen SV, Schouten GA, De Kort S, Scholtes B, Engels LG, et al. Proton pump inhibitor use is associated with an increased risk for microscopic colitis: a case-control study.
Aliment Pharmacol Ther. 2010 Nov;32(9):1124-8.

59. Ghebremariam YT, LePendu P, Lee JC, Erlanson DA, Slaviero A, Shah N, Et al. Unexpected effect of proton pump inhibitors: elevation of the cardiovascular risk factor asymmetric dimethylarginine. Circulation 2013; 128: 845.

60. FDA Drug Safety Communication: Medical Product Safety Information. http://www.fda.gov/Safety/MedWatch/SafetyInformation/SafetyAlerts for Human Medical Products/ucm 190848. htm (Accessed on January 22, 2020). 